\title{
Chewing Aid in Routine Postoperative Orders - Does it reduce Postoperative Ileus after Cesarean Section? A Randomized Control Trial
}

\author{
Aun Ali, Summaya Saeed, Amjad Siraj Memon, Mujeeb Abbasi, \\ Khursheed Samo, Rozina Mustafa
}

\begin{abstract}
OBJECTIVE: To assess effectiveness of chewing gum in women undergoing cesarean section (C-Section) on return of bowel movements.

METHODOLOGY: Randomized clinical trial was conducted at a tertiary care hospital, Karachi from January 2013 to January 2016. Total 218 participants, who were planned for Cesarean section, were randomly allocated into two groups, 109 participants in each group. In Group-I, patient's received chewing gum as routine and group II was control group. Data of all subjects were analyzed using SPSS version 20.

RESULTS: The mean age of participants was $22.68 \pm 6.31$ years. There was no significant difference between both groups in terms of age, Body Mass index, duration of surgery, parity, number of miscarriages and type of cesarean section whether elective or emergency. Significant reduction was found in terms of onset of defecation $(P<0.001)$, onset of first flatus passed $(P<0.001)$ and feeling of hunger $(P<0.003)$ between two groups.

CONCLUSION: The current study identified that routine use of chewing gum as postoperative order impacts positively on time of passing flatus, defecation, and feeling of hunger. Eventually, it will reduce suffering resulting from ileus fostering early feeding. Since it is non-expensive and easy to use method therefore, it can be included as a routine post-operative management for women undergoing cesarean section. However, it is recommended to investigate impact of using chewing gum in other abdominal surgeries.
\end{abstract}

KEYWORDS: Chewing Aid, Postoperative lleus and Cesarean Section.

This article may be cited as: Ali A, Saeed S, Memon AS, Abbasi M, Samo K, Mustafa R. Chewing Aid in Routine Postoperative Orders - Does it reduce Postoperative lleus after Cesarean Section? A Randomized Control Trial. J Liaquat Uni Med Health Sci. 2019;18 (02):109-12. doi: 10.22442/jlumhs.191820611

\section{INTRODUCTION}

Delay in resumption of bowel movement following an abdominal surgery is termed as lleus ${ }^{1}$. Among all abdominal surgeries, the most common is Cesarean section that leads to ileus secondary to post-operative changes in autonomic nervous system ${ }^{2}$. Post-operative ileus impacts on patient's clinical condition and also increases hospital stay. Post Cesarean, oral intake is withhold by many physicians as they believe in initiating intake after confirming the sign that depicts normal bowel function such as passage of flatus or stool ${ }^{3}$. Delayed oral intake may impacts on wound healing, increases the need for parental nutrition, and make individual prone to infection ${ }^{4}$. Since there is no well-established treatment modality for ileus, symptomatic treatment is done including naso-gastric tube insertion, use of local analgesia, use of non-steroidal anti-inflammatory drugs, injecting intravenous fluids, and use drinks with high carbohydrate content ${ }^{5,6}$.

Chewing gum has been used as an adjunct in recovery from ileus. It stimulates stomach that causes increased production of gastric secretions and digestive juices, which increase peristalsis ${ }^{7-9}$. Some studies supports that use of chewing gum is effective in reducing ileus ${ }^{10,11}$, whereas others reported contradictory findings ${ }^{12}$. Use of chewing gum is considered as feeding that stimulated bowel function by stimulating parasympathetic nervous system. Use of chewing gum post-operatively is cost effective and easy method to reduce ileus. This study aimed to assess effectiveness of chewing gum as routine postoperative order in women undergoing cesarean section (C-Section) on return of bowel movements. 


\section{METHODOLOGY}

This randomized controlled clinical trial was conducted over the period of 6 months after approval from ethical committee from January 2013 till January 2016 in a tertiary care hospital of Karachi, Pakistan. Patient with cesarean section either having transverse or $\mathrm{P}$ fannenstiel incision by same gynecologist were recruited in this study. Women with both elective and emergency cesarean section were included in this study. All women who underwent cesarean section and who gave consent to participate in this study were recruited, whereas, women with history of drug addiction, electrolyte imbalance, previous abdominal surgeries, pancreatitis, peritonitis, diabetes, pre-eclampsia, hypo or hyperthyroid, intra or post-operative complications, neurological disorders, muscular disorders and inability to chew gum were excluded.

Patients were randomly divided equally into intervention and control groups. Women in intervention group were given sugar free gums, after 6 hours of surgery (after recovery from anesthesia). They were asked to chew gum for three times in a day and each time to chew gum for an half an hour. During their stay they were examined for the effect of sham feeding.

All participants in intervention and control group were asked to record time of feeling hungry, passage of flatus, and defecation. A research assistant who was unaware about the intervention and even the randomization was asked to collect all these data from participants regularly.

All the data were entered into SPSS software for analysis. Both descriptive and inferential statistics were used including mean and t-test to compare results. The test were considered to be statistically significant with $95 \%$ confidence interval and p-value $<0.05$.

\section{RESULTS}

A total of 218 women who met the criteria were included in the study, out of the 245 women who presented to us during the specified time period. The mean ages of participants were $22.68 \pm 6.31$ years. There was no significant difference between both groups in terms of age, Body Mass index, duration of surgery, Parity, number of miscarriages, and type of cesarean section whether elective or emergency as shown in Table I. The mean time of passage of first flatus was $24.49 \pm 5.5$ hours in chewing group as compared to control group which was $31.40 \pm 6.6$ hours $(P<0.001)$. The mean time for passage of first defecation was $32.03 \pm 5.4$ hours where as in control group it was $40.38 \pm 6.57$ hours $(P<0.001)$ as shown in Table II. There was also significant difference between both groups in terms of onset of hunger $(P=0.003)$ as shown in Table III.

\section{TABLE I. BASELINE CHARACTERISTICS OF PARTICIPANTS}

\begin{tabular}{|c|c|c|c|}
\hline Characteristics & $\begin{array}{l}\text { Chewing } \\
\text { Gum, Mean } \\
\pm \text { SD }\end{array}$ & $\begin{array}{c}\text { Control, } \\
\text { Mean } \pm \text { SD }\end{array}$ & P- Value \\
\hline Age (Years) & $21.68 \pm 7.3$ & $23.25 \pm 6.9$ & 0.07 \\
\hline Body Mass Index & $28.31 \pm 3.6$ & $29.01 \pm 4.2$ & 0.15 \\
\hline $\begin{array}{l}\text { Parity } \\
\text { Nulliparous } \\
\text { Multiparous (two } \\
\text { or more than two } \\
\text { children) }\end{array}$ & $\begin{array}{c}\mathrm{n}=109 \\
27 \\
82\end{array}$ & $\begin{array}{c}\mathrm{n}=109 \\
30 \\
79\end{array}$ & 0.2 \\
\hline $\begin{array}{l}\text { Duration of } \\
\text { Surgery (minutes) }\end{array}$ & $32.61 \pm 9.5$ & $33.01 \pm 8.7$ & 0.15 \\
\hline $\begin{array}{l}\text { Type of C-section } \\
\text { Elective } \\
\text { Emergency }\end{array}$ & $\begin{array}{c}n=109 \\
89 \\
20\end{array}$ & $\begin{array}{c}n=109 \\
81 \\
28\end{array}$ & 0.10 \\
\hline
\end{tabular}

TABLE II. RESUMPTION OF BOWEL FUNCTION ACCORDING TO TYPE OF C-SECTION

\begin{tabular}{|l|c|c|c|}
\hline & $\begin{array}{c}\text { Emergency } \\
\text { Cases }\end{array}$ & $\begin{array}{c}\text { Elective } \\
\text { Cases }\end{array}$ & P Value \\
\hline $\begin{array}{l}\text { Onset of } \\
\text { Defecation (hours) }\end{array}$ & $37.20 \pm 7.5$ & $38.01 \pm 8.2$ & 0.75 \\
\hline $\begin{array}{l}\text { Onset of Gas } \\
\text { passage (hours) }\end{array}$ & $28.73 \pm 6.4$ & $29.30 \pm 6.3$ & 0.9 \\
\hline
\end{tabular}

TABLE III: RESUMPTION OF BOWEL FUNCTION ACCORDING TO INTERVENTION

\begin{tabular}{|l|c|c|c|}
\hline & $\begin{array}{c}\text { Chewing } \\
\text { Gum, Mean } \\
\pm \text { SD }\end{array}$ & $\begin{array}{c}\text { Control, } \\
\text { Mean } \pm \text { SD }\end{array}$ & P Value \\
\hline $\begin{array}{l}\text { Onset of } \\
\text { Defecation (hours) }\end{array}$ & $32.03 \pm 5.4$ & $40.38 \pm 6.57$ & 0.001 \\
\hline $\begin{array}{l}\text { Onset of Gas } \\
\text { passage (hours) }\end{array}$ & $24.49 \pm 5.5$ & $31.40 \pm 6.6$ & 0.001 \\
\hline $\begin{array}{l}\text { Feeling Hunger } \\
\text { (hours) }\end{array}$ & $9.33 \pm 6.7$ & $15.40 \pm 7.2$ & 0.003 \\
\hline
\end{tabular}

\section{DISCUSSION}

The results showed that intervention group that used chewing gums took lesser time for feeling of hunger, passage of flatus, and defecation. In lined with the existing literature, the study depicts a significant difference in time of passing flatus ${ }^{3}$. Similar to the study by Dehcheshmeh F Safdari $2011^{2}$ that evaluated effect of chewing gum among women undergoing elective cesarean section, the time of first bowel movement in intervention and control group 
were remarkably different. The finding is also consistent with the study by Schuster $R 2006^{9}$ that identified significant difference in time of first bowel movement among the control group and the ones using chewing gum after undergoing open sigmoid colectomy.

The findings of current study suggested that women in intervention group reported to feel hungry approximately 6 hours before in comparison to control group. This finding is in line with the study by Satij B $2006^{11}$ that suggests difference in feeling of hunger among post cesarean women. In contrast, the study by Schuster et al revealed no significant difference among patient underwent open sigmoid colectomy, in feeling of hunger among control and intervention

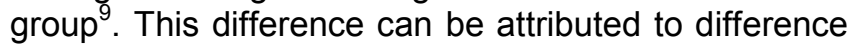
in type of surgery and smaller sample size in Schuster's study.

There was a significant difference in time first defecation between control and intervention group. Women who used chewing gum reported to defecate 8 hours early than the ones who didn't used chewing gum. This finding is supported by the existing facts in literature. In study by Abd-El-Maeboud KH $2009^{12}$ the average time difference of 9 hours was reported among the ones who used chewing gum than ones who didn't use. Similarly, the study by Hirayama I $2006^{4}$ on patients underwent colorectal surgery also reported difference of around 15 hours in first defecation among ones who used chewing gum in comparison to those who didn't used. However, the study by Quah HM $2006^{13}$ revealed no statistical difference in first defecation among ones who used chewing gum and those who didn't used following open colectomy of left side colon. This difference could relate to difference in surgery.

Passage of flatus among intervention group was reported to be 7 hours earlier among intervention group in the current study. The finding is consistent with the study by Kouba EJ $2007^{14}$ on patients who underwent radical cystectomy. However, the difference was only of 0.5 days earlier for those who used chewing gum than the control group, whereas, study by Quah HM $2006^{13}$ reported no significant difference in time of flatus passage among ones who used chewing gum than those who didn't, following open colectomy of left side colon.

The mechanism which gum chewing impacts on ileus is not known. However, literature suggests that use of gum creates sham feeding that stimulated gastrointestinal tract leading to increased gastric juices and secretions that promoted recovery from ileus ${ }^{15}$.

\section{CONCLUSION}

The current study identified that routine use of chewing gum as postoperative order impacts positively on time of passing flatus, defecation, and feeling of hunger. Eventually, it will reduce suffering resulting from ileus fostering early feeding. Since it is non-expensive and easy to use method therefore, it can be included as a routine post-operative management for women undergoing cesarean section. However, it is recommended to investigate impact of using chewing gum in other abdominal surgeries.

Ethical Permission: IRB approval letter of United Medical and Dental College Reference No/IRB-003/ UNEC/-14 dated: 22-12-14.

Conflict of interest: There was no any conflict of interest.

Funding: There was no any funding agency.

\section{REFERENCES}

1. Ge B, Zhao H, Lin R, Wang J, Chen Q, Liu L, et al. Influence of gum-chewing on postoperative bowel activity after laparoscopic surgery for gastric cancer: A randomized controlled trial. Medicine (Baltimore). 2017; 96(13): e6501. doi: 10.1097/MD.0000000000 006501.

2. Dehcheshmeh F Safdari, Salehian T, Gangi F, Beigi M. The effect of chewing sugar free gum after elective cesarean-delivery on return of bowel function in primiparous women. Qom Uni Med Sci J. 2011; 4(4): 16-20.

3. Yaghmaei $M$, Arbabi Kalati $F$, Mokhtari $M$, Behzadian A. Comparison of oral intake profiles at 2 and 8 hours following cesarean section under spinal anesthesia. Zahedan J Res Med Sci. 2010; 11(4): 43-51.

4. Hirayama I, Suzuki M, Ide M, Asao T, Kuwano H. Gum-chewingstimulates bowel motility after surgery for colorectal cancer. Hepatogastroenterology. 2006;53(68): 206-8

5. Holte K, Kehlet H. Postoperative ileus: a preventable event. Br J Surg. 2000; 87(11): 1480-93.

6. Khadije Y, Abdollahi AA, Behnampour N, Niazi M, Arya $B$, Azadrah M. Effect of chewing gum on the bowel motility after cholecystectomy. Zahdan J Res Med Sci. 2011; 13(3): 20-3.

7. Hausel J, Nygren J, Thorell A, Lagerkranser M, Ljungqvist $O$. Randomizedclinical trial of the effects of oral preoperative carbohydrateson postoperative nausea and vomiting after laparoscopic cholecystectomy. Br J Surg. 2005; 92(4): 415-21.

8. Soffer EE, Adrian TE. Effect of meal composition and sham feeding on duodenojejunal motility in humans. Dig Dis Sci.1992; 37(7): 1009-14.

9. Schuster R, Grewal N, Greaney GC, Waxman K. Gum chewing reduces ileus after elective open 
sigmoid colectomy. Arch Surg. 2006; 141(2): 174-6.

10. Hitti M. Gum may aid colon surgery recovery. [cited 2012]; Available from: http://www.webmd. com/colorectalcancer/news/20060221/gum-mayaid-colon-surgery-recovery.

11. Satij $B$, Cohen SA. Evaluation of gum chewing on the return of bowel function in cesarean-delivery patients. Obstet Gynecol. 2006; 107(4): 10 S. doi: 10.1097/00006250-200604001-00023

12. Abd-El-Maeboud KH, Ibrahim MI, Shalaby DA, Fikry MF. Gum chewing stimulates early return of bowel motility after caesarean section. BJOG. 2009; 116(10): 1334-9. doi: 10.1111/j.1471-0528. 2009.02225.x.

13. Quah HM, Samad A, Neathey AJ, Hay DJ, Maw
A. Does gum chewing reduce postoperative ileus following open colectomy for left-sided colon and rectal cancer? A prospective randomized controlled trial. Colorectal Dis. 2006; 8(1): 64-70.

14. Kouba EJ, Wallen EM, Pruthi RS. Gum chewing stimulates bowel motility in patients undergoing radical cystectomy with urinary diversion. Urology. 2007; 70(6): 1053-6.

15. Choi H, Kang SH, Yoon DK, Kang SG, Ko HY, Moon du G, et al. Chewing gum has a stimulatory effect on bowel motility inpatients after open or robotic radical cystectomy for bladder cancer: a prospective randomized comparative study. Urology.2011; 77(4): 884-90. doi: 10.1016/ j.urology.2010.06.042.

AUTHOR AFFILIATION:
Dr. Aun Ali
Associate Professor, Department of Surgery
United Medical and Dental College
Karachi, Sindh-Pakistan.
Dr. Summaya Saeed
Assistant Professor, Department of Surgery
Dow Medical College, Karachi, Sindh-Pakistan.
Dr. Amjad Siraj Memon
Professor, Department of Surgery
Dow Medical College, Karachi, Sindh-Pakistan.
Dr. Mujeeb Abbasi (Corresponding Author)
Associate Professor, Department of Surgery
Dow Medical College, Karachi, Sindh-Pakistan.
Email: abbasimujeeb@gmail.com
Dr. Khursheed Samo
Assistant Professor, Department of Surgery
Dow Medical College, Karachi, Sindh-Pakistan.
Dr. Rozina Mustafa
Professor, Department of Gynaecology and Obstetrics
United Medical and Dental College
Karachi, Sindh-Pakistan.

